\title{
Multifactorial study of mobile phone dependence in medical students: Relationship to health-related lifestyle, Type A behavior, and depressive state
}

\author{
Masahiro Toda ${ }^{1^{*}}$, Satoko Ezoe ${ }^{2}$ \\ ${ }^{1}$ Department of Pharmacology, Osaka Dental University, Osaka, Japan; *Corresponding Author: toda-m@cc.osaka-dent.ac.jp \\ ${ }^{2}$ Shimane University, Health Administration Center Izumo, Shimane, Japan
}

Received 29 October 2012; revised 3 December 2012; accepted 11 December 2012

\begin{abstract}
We investigated factors contributing to mobile phone dependence. To 139 medical students, we administered a self-reporting questionnaire designed to evaluate mobile phone dependence, health-related lifestyle, patterns of behavior, and depressive state. Multivariate logistic regression analysis revealed that scores for poor healthrelated lifestyle, Type A behavior pattern, and presence of depression are independently associated with degree of mobile phone dependency. These findings suggest that persons with an unhealthy lifestyle, Type A behavior traits, or depression might benefit from mobile phone use guidance.
\end{abstract}

Keywords: Mobile Phone Dependence; Health-Related Lifestyle; Patterns of Behavior; Depressive State; Medical Students

\section{INTRODUCTION}

In Japan, in March 2011 there were about 120 million mobile phones in use, which is almost the same as the total population [1]. Along with the rapid proliferation of mobile phones, various social issues have arisen, including their use in public places and excessive use or even dependence. Viewing problematic mobile phone use as a type of technostress [2], to gauge mobile phone dependence and identify high-risk groups, we were quick to design the Mobile Phone Dependence Questionnaire (MPDQ) questionnaire, subsequently confirming its reliability and validity [3].

In recent studies, we found that mobile phone dependency is associated with unhealthy lifestyle [4,5], extrovert or neurotic personality traits [5], and maternal affectionate constraint in childhood [6]. Other factors that may also contribute to mobile phone dependence remain to be studied. For example, we think that more multifactorial research is needed. Consequently, in the present study, using logistic regression analysis, we examined associations between mobile phone dependence and demographic characteristics, health-related lifestyle, patterns of behavior, and depressive state.

\section{MATERIALS AND METHODS}

\subsection{Subjects}

We recruited 139 university students from the Faculty of Medicine at Shimane University. After the protocol received the approval of the institute's review board and informed consent was obtained from each participant, the participants filled out a set of self-reporting questionnaires designed to evaluate mobile phone dependence, health-related lifestyle, behavior pattern, and depressive state. The answers of the 130 respondents (47 males, 83 females) who properly completed all the questionnaire items were statistically analyzed. Mean $( \pm$ SD) age for males was $19.3 \pm 1.8$ years and for females $18.7 \pm 0.9$ years.

\subsection{Mobile Phone Dependence}

Mobile phone dependence was evaluated using the MPDQ [3], a self-rating questionnaire which consists of 20 items. Each response is scored on a Likert scale $(0,1$, $2,3)$. Likert scores for each item are then summed to provide a quantitative overall mobile phone dependence score ranging from 0 to 60 . Higher scores indicate greater dependence. Subjects in the highest quartile were put in the high-dependence category.

\subsection{Health-Related Lifestyle}

Health-related lifestyle was evaluated using the Health Practice Index (HPI) [7,8], in which 1 point is accumulated for each desirable response on 8 items (desirable criteria are shown in parentheses): smoking habits (not 
smoking cigarettes), drinking habits (not consuming alcohol every day), daily consumption of breakfast (eating every morning), appropriate daily duration of sleep (7 or more hours) and work (10 or less hours), regular physical activity (1 or more times per week), appropriate levels of subjective stress (low to moderate), and nutritionally balanced diet (eating a nutritionally balanced diet). Higher scores indicate healthier lifestyle. Respondents with 6 - 8 points were allocated to the good, and those with 0 - 5 points to the poor, category [9]. Based upon the lifestyle study by Belloc and Breslow [10], and taking into consideration cultural differences, the question items, phrasing, and scoring were designed for Japanese subjects.

\subsection{Patterns of Behavior}

Type A behavior patterns vary according to culture and nationality [11]. We therefore assessed patterns of behavior using the Tokai University Type A Pattern Scale [11,12] designed for Japanese population. The scale consists of 11 items with total score ranging from 0.25 to 98.75 . Subjects were categorized as having either Type A or Type B behavior patterns: persons with scores of 43.1 points or more are placed in the Type A category [11].

\subsection{Depressive State}

Depressive state was assessed using the Beck Depression Inventory-II (BDI-II) [13], a self-rating questionnaire which consists of 21 items with total score ranging from 0 to 63 . Higher scores indicate greater depression. The reliability and usefulness of the Japanese version of the BDI-II have been confirmed [14]. Subjects were categorized as having either no or minimal, or mild or greater, depression (cutoff point 13/14) [13].

\subsection{Statistical Analysis}

Univariate and subsequent multivariate logistic regression analyses were applied to identify possible associations between mobile phone dependence and each factor (demographic characteristics, health-related lifestyle, patterns of behavior, and depressive state). All variables with a $p$ value $<0.2$ in the univariate analysis were included in the multivariate analysis (stepwise backward elimination) with age adjustment [15]. Statistical significance was set at $p<0.05$ and the confidence interval was $95 \%$.

\section{RESULTS}

Table 1 shows scores for each questionnaire. Scores for mobile phone dependence, mean 26.5, ranged from 6 to 54 . Respondents in the highest quartile were put in the high-dependence category (cutoff point 33/34).

Table 2 shows personal characteristics related to mobile phone dependence category. Univariate logistic regression results revealed a statistically significant relationship between mobile phone dependence and health-related lifestyle (OR $=2.34, p<0.05)$, predominance of Type A behavior traits (OR $=2.49, p<0.05)$, and depressive state $(\mathrm{OR}=3.04, p<0.05)$ (Table 3). In addition to these variables, gender and mode of residence (variables with a $p$ value $<0.2$ ) were included in age-

Table 1. Scores for each questionnaire.

\begin{tabular}{|c|c|c|c|}
\hline & Mean & Range & $\mathrm{SD}$ \\
\hline $\begin{array}{l}\text { Mobile Phone Dependence } \\
\text { Questionnaire (MPDQ) }\end{array}$ & 26.5 & $6-54$ & 9.1 \\
\hline Health Practice Index (HPI) & 5.4 & $3-8$ & 1.1 \\
\hline $\begin{array}{l}\text { Type A Pattern Scale of Tokai } \\
\text { University }\end{array}$ & 38.4 & $17.5-66.5$ & 8.7 \\
\hline $\begin{array}{l}\text { Beck Depression Inventory-II } \\
\text { (BDI-II) }\end{array}$ & 8.4 & $0-36$ & 8.6 \\
\hline
\end{tabular}

Table 2. Subject characteristics and mobile phone dependence category.

\begin{tabular}{|c|c|c|}
\hline & $\begin{array}{c}\text { Low-dependence } \\
\text { n (\%) }\end{array}$ & $\begin{array}{c}\text { High-dependence } \\
\text { n (\%) }\end{array}$ \\
\hline \multicolumn{3}{|l|}{ Gender } \\
\hline Male & 39 (39.8) & $8(25.0)$ \\
\hline Female & $59(60.2)$ & $24(75.0)$ \\
\hline \multicolumn{3}{|l|}{ Department } \\
\hline Medicine & $58(59.2)$ & 15 (46.9) \\
\hline Nursing & $40(40.8)$ & $17(53.1)$ \\
\hline \multicolumn{3}{|c|}{ Mode of residence } \\
\hline In a family & 14 (14.3) & $1(3.1)$ \\
\hline Solitary & $84(85.7)$ & 31 (96.9) \\
\hline \multicolumn{3}{|c|}{ Health-related lifestyle } \\
\hline Good & $54(55.1)$ & $11(34.4)$ \\
\hline Poor & 44 (44.9) & $21(65.6)$ \\
\hline \multicolumn{3}{|c|}{ Patterns of behavior } \\
\hline Type B & 79 (80.6) & $20(62.5)$ \\
\hline Type A & 19 (19.4) & $12(37.5)$ \\
\hline \multicolumn{3}{|l|}{ Depression } \\
\hline Absent & $80(81.6)$ & 19 (59.4) \\
\hline Present & $18(18.4)$ & $13(40.6)$ \\
\hline
\end{tabular}


Table 3. Univariate and multivariate logistic regression analyses to identify factors associated with high mobile phone dependency.

\begin{tabular}{|c|c|c|c|c|c|c|}
\hline \multirow[b]{2}{*}{ Candidate factors } & \multicolumn{3}{|c|}{ Univariate analysis } & \multicolumn{3}{|c|}{ Multivariate analysis (final model) ${ }^{*}$} \\
\hline & $\begin{array}{c}\text { Crude } \\
\text { odds ratio } \\
\end{array}$ & $\begin{array}{c}95 \% \text { Confidence } \\
\text { interval }\end{array}$ & $\mathrm{p}$ value & $\begin{array}{c}\text { Adjusted } \\
\text { odds ratio }\end{array}$ & $\begin{array}{l}\text { 95\% Confidence } \\
\text { interval }\end{array}$ & $\mathrm{p}$ value \\
\hline Gender (1, female; 0 , male) & 1.98 & $0.81-4.86$ & 0.134 & & & \\
\hline Department (1, nursing; 0, medicine) & 1.64 & $0.74-3.67$ & 0.225 & & & \\
\hline Mode of residence ( 1 , solitary; 0 , in a family) & 5.17 & $0.65-40.95$ & 0.120 & & & \\
\hline Health-related lifestyle (1, poor; 0, good) & 2.34 & $1.02-5.38$ & 0.045 & 2.51 & $1.05-6.04$ & 0.039 \\
\hline Patterns of behavior (1, Type A; 0, Type B) & 2.49 & $1.04-5.98$ & 0.040 & 2.73 & $1.04-7.19$ & 0.042 \\
\hline Depression (1, present; 0, absent) & 3.04 & $1.27-7.27$ & 0.012 & 2.80 & $1.13-6.97$ & 0.027 \\
\hline
\end{tabular}

*Using a backward stepwise procedure, non-significant factors were removed from the model until only significant $(p<0.05)$ factors remained.

adjusted multivariate logistic regression analysis. Using a backward stepwise procedure, non-significant variables were removed from the multivariate model until only significant $(p<0.05)$ variables remained. As a result, poor health-related lifestyle (OR $=2.51, p<0.05$ ), Type A behavior ( $\mathrm{OR}=2.73, p<0.05)$, and presence of depression (OR $=2.80, p<0.05)$ were found to be independently associated with high mobile phone dependency.

Meanwhile, univariate logistic regression analysis revealed no significant relationships between particular lifestyle factors and mobile phone dependence (Table 4). Moreover, when, in place of health-related lifestyle, "consumption of breakfast" and "physical activity" (variables with a $p$ value $<0.2$ ) were included in the abovementioned multivariate model, in the backward stepwise procedure both were removed prior to any other factors (Type A behavior, depressive state, gender, and mode of residence).

\section{DISCUSSION}

Type A individuals are characteristically prone to impatience and communicate a sense of urgency about time. A previous study has also reported that mobile phone dependence was associated with two facets of the UPPS Impulsive Behavior Scale, urgency and lack of perseverance [16]. Individuals with impetuous and impatient characteristics may want to make contact with others at any time and place, which may consequently result in use of mobile phones in public places even when such use is considered to be a nuisance. Thus, Type A individuals may require more intensive guidance about mobile phone use.

It has been reported that excessive mobile phone use is associated with depression $[17,18]$. In the present study, we also found a significant relationship between mobile phone dependence and depressive state. These findings suggest that, for depressed individuals, mobile phones may be a stress-coping tool. By mobile phone, they may be able to ask others' advice about their distress and furthermore express their feelings better than by directly face-to-face communication. This hypothesis is supported by previous studies which suggested that mobile phones may increase social support [19,20]. Unfortunately, however, because this study was cross-sectional, we cannot conclusively establish causality. Longitudinal studies are required. Incidentally, in a previous study, we found no significant relationship between mobile phone dependence and depressive state evaluated using the Zung Self-Rating Depression Scale (Zung-SDS) [5]. This finding may be due to different depressive state scoring criteria in BDI-II and Zung-SDS. This may be clarified in a future study that uses these two instruments at the same time.

Consistent with our previous findings [4,5], there was a significant relationship between mobile phone dependence and comprehensive health-related lifestyle. These findings suggest that people who excessively use mobile phones may benefit from more comprehensive guidance, including how to follow a healthier lifestyle. Other previous studies have also suggested that excessive mobile phone use may be associated with poor lifestyle habits, such as smoking or daily alcohol consumption [17,21]. In the present study, however, no significant relationships were found between particular lifestyle factors and mobile phone dependence. This may have been due to the inclusion of proportionally fewer individuals with detrimental smoking or drinking habits. Larger populations are needed for future studies.

This research has several limitations. As already mentioned in the discussion, this study was cross-sectional, and the sample size was too small to provide conclusive results. Furthermore, our questionnaire did not include items specific to smartphones. In recent years, smartphones have rapidly come into widespread use, and, according to a survey carried out by comScore, Inc. (2012), in June 2012, the penetration rate in Japan is over 20\% 
Table 4. Percentage of respondents with poor health-related lifestyle and results of univariate logistic regression analysis to identify factors associated with high mobile phone dependency.

\begin{tabular}{|c|c|c|c|c|c|}
\hline $\begin{array}{l}\text { Health-related lifestyle factors } \\
\qquad(1, \text { good; } 0 \text {, poor })\end{array}$ & $\begin{array}{l}\text { Low-dependence } \\
\text { n (\%) }\end{array}$ & $\begin{array}{l}\text { High-dependence } \\
\text { n (\%) }\end{array}$ & Crude odds ratio & 95\% Confidence interval & $p$ value \\
\hline Smoking habits & $0(0)$ & $2(6.3)$ & $\mathrm{NC}^{*}$ & - & - \\
\hline Drinking habits & $0(0)$ & $1(3.1)$ & $\mathrm{NC}^{*}$ & - & - \\
\hline Consumption of breakfast & $14(14.3)$ & $8(25.0)$ & 0.50 & $0.19-1.33$ & 0.166 \\
\hline Duration of sleep & 75 (76.5) & $23(71.9)$ & 1.28 & $0.52-3.14$ & 0.596 \\
\hline Duration of work & 43 (43.9) & $14(43.8)$ & 1.01 & $0.45-2.25$ & 0.990 \\
\hline Physical activity & $10(10.2)$ & 7 (21.9) & 0.41 & $0.14-1.18$ & 0.096 \\
\hline Subjective stress & $26(26.5)$ & $12(37.5)$ & 0.60 & $0.26-1.40$ & 0.239 \\
\hline Nutritional balance & 74 (75.5) & 23 (71.9) & 1.21 & $0.49-2.96$ & 0.682 \\
\hline
\end{tabular}

* Odds ratio not calculable because of zero value.

[22]. Smartphones are more like tablet computers than mobile phones, and therefore may herald another change in the way mobile telecommunication are used. Based on recent developments, we are planning further studies.

In conclusion, the major finding of this study is that, when adjusted for other factors, poor health-related lifestyle, Type A behavior, or presence of depression may be statistically significantly associated with high mobile phone dependency. Persons with an unhealthy lifestyle, Type A behavior traits, or depression might benefit from mobile phone use guidance.

\section{REFERENCES}

[1] Ministry of Internal Affairs and Communications (2011) White paper: Information and communications in Japan, 2011.

http://www.soumu.go.jp/johotsusintokei/whitepaper/eng/ WP2011/2011-index.html

[2] Brod, C. (1984) Technostress: The human cost of the computer revolution. Addison-Wesley, Reading.

[3] Toda, M., Monden, K., Kubo, K. and Morimoto, K. (2004) Cellular phone dependence tendency of female university students. Japanese Journal of Hygiene, 59, 383-386. doi:10.1265/jjh.59.383

[4] Toda, M., Monden, K., Kubo, K. and Morimoto, K. (2006) Mobile phone dependence and health-related lifestyle of university students. Social Behavior and Personality, 34, 1277-1284. doi:10.2224/sbp.2006.34.10.1277

[5] Ezoe, S., Toda, M., Yoshimura, K., Naritomi, A., Den, R. and Morimoto, K. (2009) Relationships of personality and lifestyle with mobile phone dependence among female nursing students. Social Behavior and Personality, 37, 231-238. doi:10.2224/sbp.2009.37.2.231

[6] Toda, M., Ezoe, S., Nishi, A., Mukai, T., Goto, M. and Morimoto, K. (2008) Mobile phone dependence of female students and perceived parental rearing attitudes.
Social Behavior and Personality, 36, 765-770. doi:10.2224/sbp.2008.36.6.765

[7] Ezoe, S. and Morimoto, K. (1994) Behavioral lifestyle and mental health status of Japanese factory workers. Preventive Medicine, 23, 98-105. doi:10.1006/pmed.1994.1014

[8] Morimoto, K. (2000) Lifestyle and health. Japanese Journal of Hygiene, 54, 572-591. doi:10.1265/jjh.54.572

[9] Toda, M., Makino, H., Kobayashi, H. and Morimoto, K. (2007) Health-related lifestyle and patterns of behavior related to health effects of leisure travel. Social Behavior and Personality, 35, 287-294. doi:10.2224/sbp.2007.35.3.287

[10] Belloc, N.B. and Breslow, L. (1972) Relationship of physical health status and health practices. Preventive Medicine, 1, 409-421. doi:10.1016/0091-7435(72)90014-X

[11] Hosaka, T. and Tagawa, R. (1987) The Japanese characteristic of Type A behavior pattern. The Tokai Journal of Experimental and Clinical Medicine, 12, 287-303.

[12] Hosaka, T. and Tagawa, R. (1989) The coronary-prone behavior pattern among Japanese: Its comparison with Type A behavior pattern. Japanese Journal of Psychosomatic Medicine, 29, 527-536.

[13] Beck, A.T., Steer, R.A. and Brown, G.K. (1996) Manual for the Beck Depression Inventory-II. Psychological Corporation, San Antonio.

[14] Kojima, M., Furukawa, T.A., Takahashi, H., Kawai, M., Nagaya, T. and Tokudome, S. (2002) Cross-cultural validation of the Beck Depression Inventory-II in Japan. Psychiatry Research, 110, 291-299. doi:10.1016/S0165-1781(02)00106-3

[15] Hosmer, D.W. and Lemeshow, S. (2000) Applied logistic regression. Wiley, New York. doi:10.1002/0471722146

[16] Billieux, J., Van der Linden, M., D’Acremont, M., Ceschi, G. and Zermatten, A. (2007) Does impulsivity relate to 
perceived dependence on and actual use of the mobile phone? Applied Cognitive Psychology, 21, 527-537. doi:10.1002/acp.1289

[17] Sánchez-Martínez, M. and Otero, A. (2009) Factors associated with cell phone use in adolescents in the community of Madrid (Spain). Cyberpsychology \& Behavior, 12, 131-137. doi:10.1089/cpb.2008.0164

[18] Yen, C.F., Tang, T.C., Yen, J.Y., Lin, H.C., Huang, C.F., Liu, S.C. and Ko, C.H. (2009) Symptoms of problematic cellular phone use, functional impairment and its association with depression among adolescents in Southern Taiwan. Journal of Adolescence, 32, 863-873. doi:10.1016/j.adolescence.2008.10.006

[19] Igarashi, T., Takai, J. and Yoshida, T. (2005) Gender differences in social network development via mobile phone text messages: A longitudinal study. Journal of Social and Personal Relationships, 22, 691-713. doi:10.1177/0265407505056492

[20] Rettie, R. (2008) Mobile phones as network capital: Facilitating connections. Mobilities, 3, 291-311. doi:10.1080/17450100802095346

[21] Koivusilta, L., Lintonen, T. and Rimpelä, A. (2005) Intensity of mobile phone use and health compromising behaviours: How is information and communication technology connected to health-related lifestyle in adolescence? Journal of Adolescence, 28, 35-47. doi:10.1016/j.adolescence.2004.05.004

[22] comScore, Inc. (2012) Japan smartphone surge. http://www.comscore.com/Press_Events/Press_Releases/ 2012/8/Japan_Smartphone_Surge 